\title{
The Intercultural Competence in Education Era 4.0: A Learning Strategy for Students of Elementary School in Indonesia
}

\author{
Harmelia Tulak ${ }^{1}$, Hengki Wijaya ${ }^{2}$, Susanna Vonny N. Rante ${ }^{3}$, Nurmadiah ${ }^{4}$, Helaluddin ${ }^{5}$ \\ \{harmeliatulak@ukitoraja.ac.id ${ }^{1}$, hengkilily1988@ gmail.com ${ }^{2}$, vonny@ukitoraja.ac.id ${ }^{3}$ \} \\ 1,3,4,5Indonesian Christian University of Toraja, Toraja Indonesia \\ ${ }^{2}$ Sekolah Tinggi Filsafat Jaffray Makassar, Makassar Indonesia
}

\begin{abstract}
Diversity in social life is a sure thing. But in reality, various problems and conflicts have arisen that are caused by intercultural competencies that are not shared by every individual. The concept of intercultural competence is the essential thing today due to several factors, namely globalization, the complexity of social life, and the pace of technological development. Intercultural competence is as the ability of each to understand the culture of others and how he can communicate well with people from that culture. This article was developed using the Systematic Literature Review (SLR) method in presenting an intercultural competence learning strategy to students in elementary schools. This article focuses on the intercultural competence learning strategy by integrating technology into class activities as one of the characteristics of learning in the education era 4.0.
\end{abstract}

Keywords: intercultural education, intercultural competence, learning strategy

\section{Introduction}

Today, various global issues emerge with many impacts and challenges. Concerns about terrorism, racism, global warming, the problem of immigrants, to the onslaught of technology have unimportant consequences and effects on the lives of the world population. In the field of technology, the world feels small and small because of the presence of the internet, social media, and traveling activities abroad at a low cost [1]. This condition certainly has an impact on the changing social order of the world community.

One of the world's issues that is becoming a global problem today is the issue of the diversity of the world's population. As we know that the issue of diversity turns out to bring the potential for conflict that is not simple. The problem of global terrorism to many local community conflicts caused by cultural differences [2]. These conditions, it is necessary to have adequate and appropriate solution steps in overcoming the problems about these cultural differences.

The education sector is a field of human life that is inseparable from the influence of various global issues. Multiple forces from global issues have an impact on the changing paradigm and educational process. The presence of the industrial revolution era 4.0 has changed the learning strategies used by teachers because of the demands of the times. These factors include advances in technology products, the presence of generation $\mathrm{Z}$ and generation A, needs for global competence, etc. [3]. 
One of the complicated challenges that must be faced by the world of global education comes from the students themselves. Problems that must be met by students not only dwell on cognitive aspects but also extend to psychological aspects [4]. Changes in family or community structure, violence and abuse, ethnic or ethnic differences, and skin color differences bring mental stress to students. For this reason, it takes an international competency that can prevent and minimize the various problems of these students. Competence, which means intercultural competency, which serves to equip students in acting and behaving towards cultural differences among the world's population [5].

Being someone different or being part of a different ethnicity is sometimes not considered. These conditions become a reason for acts of discrimination [6]. Minorities are treated passively and sometimes not recognized and respected. Living in a context characterized by pluralism and heterogeneity is not an easy thing. The process that leads to social exclusion began to occur in the first years of the lives of children in school [7].

The increasing escalation of world tension caused by the absence of attitudes and behavior that respects differences in others is a challenge for the world of education. International competencies need to be taught at all levels of education across the globe, confirmed by Habib who states that the logic in adopting international thinking skills in pedagogical practices is a necessity of the times, both through education, business media, technology, and interactions between people in the world [8]. Furthermore, Zhao states that what is needed by small groups of people has now become a necessity for all professions, such as diplomats, translators, crosscultural communication consultants, tour guides, and others [9].

Given the limited amount of literature on intercultural education in Indonesia, the authors consider providing a review of this issue. Intercultural competencies which have so far been penetrated higher education need to be extended to elementary school. Also, the design of intercultural competency learning needs to be applied to elementary schools using a technology approach as a characteristic of learning in the education era 4.0. The intercultural competencies can be mastered by students early on. 


\section{Methods}

The presentation of this article aims to provide additional literature on the description of intercultural learning in Indonesia, which is indeed still minimal. This article was developed using the Systematic Literature Review (SLR) method to present intercultural competency learning concepts \& strategies for elementary school students in Indonesia. This SLR method is considered capable of contributing to the academic literature that has existed reliably and accurately [10].

The activity of searching data sources in this study was carried out by using a database on Google Scholar by using search keywords "intercultural competences" and "education/ learning of IC." The search results in 50 test results, which are then studied to determine which text is relevant to the topic of this article. Of the 50 articles analyzed and produced 18 texts that were considered relevant and appropriate for further analysis. The analysis process is carried out to create a comprehensive and systematic review of intercultural competencies and learning at the level of primary education.

\section{Discussion}

\subsection{Multicultural, Cross-cultural, \& Intercultural}

The term multicultural and intercultural is sometimes exchanged for meaning. Multiculturality is often seen as a result of the cohabitation of different cultures, while the intercultural concept is more often associated with the world of education [11]. Furthermore, intercultural is a process that allows people from different backgrounds to communicate between them while maintaining their own culture while respecting the culture of others. Multiculturalism is used in describing elements of diversity in schools or communities, while intercultural is aimed at education policies and practices in the field [12].

The term intercultural is often even equated with the meaning cross-cultural. Gudykunst \& Kim mentions that cross-cultural terms imply a comparison of several cross-cultural phenomena [13]. On the other hand, when we are discussing communication and interaction from different cultures, we use the term intercultural [14]. The term intercultural is present when there are some people from different cultures who meet and interact with each other. Interculturalism is not a social structure as in multiculturalism because intercultural is an interaction process [15].

\subsection{Intercultural Education}

Intercultural education is crucial for students in looking at their future. In the current educational discourse, diversity is an important concept that demands attention and consideration for educators and the government. For this reason, the teacher holds a central role in considering various forms of difference [16].

The influence of globalization and community migration makes intercultural education not a unique thing but has become a community need that continues to turn into a multicultural and multilingual society [17]. Intercultural education has been shown to bring positive results in reducing prejudice to racial differences, developing the social identity, celebrating diversity, and promoting human rights and citizenship [18].

There are three aspects of intercultural education, namely: teaching classes with diverse students, intercultural learning methods, and intercultural learning material [19]. Furthermore, UNESCO said there are several principles of intercultural education which include: (1) 
fostering an attitude of respect for foreign cultural identities, (2) providing knowledge, attitudes, and cultural skills to participate in social societies, and (3) giving knowledge, attitudes, and skills for students to be able to provide respect, understanding, and solidarity with each personal, ethnic, social, cultural, religious and national differences.

The purpose of intercultural education is to reform schools so that all students are free from the treatment of differences in sex, race, cultural origin, or social class which leads to equal education and opportunities for educational mobility [20]. In line with Banks, Hernandez \& Hermosilla stated that intercultural education has a global and inclusive vision that aims to review in ensuring all students in the world get quality education based on the principle of social justice [21]. Thus, teachers, as intercultural educators, must be able to bridge linguistic and communication gaps between students and their school environment [22].

Another goal of intercultural education is to narrow the social inequalities that occur in society. Attention to the existence of differences from cross-cultural approaches is a crucial role in ensuring all students learn about respect for others, respect each variation, and increase knowledge about culture [21]. That is, with intercultural education, students are expected to have the knowledge and skills to respond to differences early.

\subsection{Intercultural Competence}

Takeuchi states that the concept of intercultural competence is considered an important attribute to foster global citizenship[23]. The definition of intercultural competence is indeed complicated to decipher. The literature does not provide definitive answers to intercultural competencies [24]. But intercultural competence is directed at tolerant attitudes and behaviors and respect for other cultures.

Intercultural competence is defined as the ability to communicate effectively in crosscultural contexts [25]. Deardorff mentions that this competence is also interpreted as the ability to develop knowledge, skills, and attitudes that are targeted in inter-cultural interactions (2016). In line with these two opinions, Spitzberg \& Changnon cited by Cui mentioning that intercultural competence is interpreted as a communication capability with other people from different backgrounds, representing different cultural orientations in the world [14].

More generally, Sercu mentions several definitions of intercultural competence, namely: (1) willingness to engage with foreign cultures, (2) self-awareness and the ability to see oneself from an outside perspective, (3) the ability to see the world through angles view of others, (4) ability to overcome uncertainty, (5) ability to act as cultural mediator, (6) ability to evaluate other people's perspectives, (7) ability to consciously use cultural learning skills and read various cultural contexts, and (8) understand that individuals cannot be reduced to their collective identity [26].

Intercultural competence is also defined as competence that requires knowledge, motivation, skills in verbal and nonverbal communication, and appropriate and effective behavior [27]. Intercultural competence is often associated with tolerance for ambiguity, flexible action, communicative awareness, the discovery of knowledge, respect for others, and empathy with others [28]. But what needs to be emphasized is that intercultural competencies are bound to the context. That is, the same behavior is sometimes felt differently by others, depending on the context. 


\subsection{Models of Intercultural Competence Learning}

A broad definition of intercultural competence (IC) requires experts to clarify the IC concept. Thus, education practitioners try to develop various IC models that include multiple dimensions in it. All IC models have similar but different aspects of emphasis or component details. But basically, all of these models include concern (self and others), clear thinking, intercultural knowledge, and skills that lead to effective communication and behavior as a result of the IC [29].

Following are some intercultural competence models developed by experts.

1) Pyramid Model by Deardorff, this model consists of five parts consisting of:

a) requisite attitude: respect for other cultures, open to intercultural and other cultural learning, and curiosity and exploration

b) knowledge \& comprehension: individual awareness of the culture and culture of others, awareness of the influence of social factors on language usage \& cultural reading skills, and having information about the culture and understanding it

c) skills: listening to other people from different cultures, observing the culture of others, interpreting other people's cultures, and evaluating and connecting various cultures

d) desired internal outcomes: adapting to new cultures, flexibility in choosing and using appropriate communication styles, and empathy

e) Desired external outcome: have communication skills and appropriate and effective behavior to achieve goals based on knowledge, skills, and intercultural attitudes.

2) Ruben Model

The model developed by Ruben consists of seven dimensions which include: (a) respect, (b) attitude toward interaction, namely responding to others without judgment, (c) getting used to knowledge, that is understanding other people who might have a point of view different from our perspective), (d) empathy, (e) mission-role behavior or flexible in acting and interacting, (f) interaction management or taking part of a problem and resolving it, and $(\mathrm{g})$ tolerating to uncertainty or the ability of each in reacting/responding to new situations.

3) Byram Model

Furthermore, the Byram model is divided into five main components, namely:

a) Attitude

b) Knowledge

c) Interpreting and relating skills, namely the skill of interpreting other cultural events and connecting them to their cultural situation

d) Exploring and interacting skills, namely the ability to obtain new information about the culture and its implementation, and

e) Critical cultural awareness, namely the ability of individuals to evaluate their learning and other cultural perspectives.

4) Fantini Model

The last model developed by experts is the Fantini model, which consists of intercultural knowledge, intercultural attitude, intercultural skills, and cross-cultural awareness.

\subsection{IC Learning with Technology}

In today's contemporary era, cultural teaching and intercultural education must indeed be prioritized [30]. Intercultural learning is done by designing a process of interaction among people from various cultures based on equality and mutual respect [15]. Furthermore, interculturalism is not possible if it is not done through a communication process.

There are several principles of intercultural learning, namely: 
1) Intercultural teaching must be included in language learning, not as a stand-alone lesson

2) Intercultural learning must be implicit and explicit with clear outcomes

3) Intercultural learning must encourage the learning process and knowledge acquisition for students

4) Intercultural learning must consider the diversity of students and contexts with various inter-cultural language activities

5) Intercultural learning must aim to develop intercultural competencies for students rather than the competence of native speakers [31].

Learning intercultural competencies using media and technology products has been carried out by teachers and researchers. Usually, ICs are taught in an integrated manner with precise subjects and are not done separately. One of the items that are often integrated with IC learning is foreign languages. However, it is also possible for ICs to be taught through other subjects. Some technology products that are widely used in IC learning include holograms, VR technology, artificially intelligent, cloud, and others [32]. Furthermore, Sintawati also stated that various intercultural skills could be taught using the help of Facebook, podcasts, twitter, movie maker, email, skype, blog, moodle, and online forums [32].

\subsection{IC in Language Learning}

Today, language teaching is not only focused on the level of grammar but also extends to other aspects. One of the elements in question is achieving communicative competence in intercultural education. That is, culture is a crucial component in language learning that is intended to be addressed. The purpose of current language teaching has involved several vital aspects, namely awareness, knowledge, and the development of several skills related to other cultures [33]. Language learning is no longer defined in communicative competence alone but also extends to one's ability to act in a way that is linguistical, sociolinguistic, and pragmatic [34].

In practice, there are still many teachers who have difficulty implementing intercultural education in classroom learning. Sercu claims that most teachers want to integrate intercultural competencies into their teaching environment, but they are still confused about the meaning of intercultural itself [26]. The same thing was expressed by Atay, who emphasized that prospective teachers think that they do not have enough opportunities to learn about other cultures [35].

For language learning in elementary schools, teachers must be able to find strategies in introducing ICs in class. IC learning can be submitted to students in grades V and VI. One approach that can be applied is by presenting readings by selecting topics related to the target culture that are addressed through controversial issues that occur [32]. For example, the teacher can look for reference references that relate to racial conflicts that arise in America and other European countries. After the reading activity is complete, the teacher invites students to discuss the reading topic by emphasizing the importance of IC in learning. To be more interesting, the teacher can present the reading through technological tools, such as blogs, social media (Instagram, Twitter, Facebook), and others.

In language learning, learning is usually inserted also about literature. Literature is very closely related to cultural content. For this reason, learning intercultural competence (IC) can also be taught through the literary learning material. The literary material can be in the form of folk tales, traditional stories, various dances from other countries, and the introduction of conventional clothes /other countries. If all this time literature learning in elementary schools contained more local cultural content, it would not hurt the teacher to include folklore from different countries to introduce that the culture in this world is very diverse. 
Apart from learning Indonesian and English, IC can also be integrated into social and historical lessons. In discussing the history of the continent or individual countries, the teacher can present various conflicts and other issues related to racial and cultural differences. Thus, elementary school students have early knowledge that differences in the world are natural. Teachers can focus on the process of how students should act and behave towards that diversity.

\section{Conclusion}

The complexity of the various problems faced by the world of education in the $21 \mathrm{st}$ century caused by global issues needs to be addressed seriously. Racial discrimination, hegemony towards minorities, and gender inequality that occur in all parts of the world are complex problems that also affect the world of education. The experts agreed to minimize the various conflicts caused by human diversity. One of them is by encouraging educators to teach intercultural competence (IC) in every formal education institution, both at the level of primary education to higher education.

Intercultural competence (IC) is a skill that must be mastered by students in facing the world of work in the 21 st century. IC is a skill that requires students to behave and act appropriately when they have to live together and interact with other world citizens with different cultural backgrounds. Given the importance of these skills, Intercultural competence (IC) should be taught as early as possible, namely at the level of primary education.

\section{References}

[1] G. Günçavdı and S. Polat, "Level of Intercultural Competence of International Students at Kocaeli University," Univers. J. Educ. Res., vol. 4, no. 12A, pp. 39-45, 2016.

[2] M. Brigg and R. Bleiker, Mediating Across Difference: Oceanic and Asian Approaches and Cultures. Clevedon: Multilingual Matters, 2011.

[3] Helaluddin and Alamsyah, "Kajian Konseptual tentang Social-emotional Learning (SEL) dalam Pembelajaran Bahasa," Al-Ishlah J. Pendidik., vol. 11, no. 1, pp. 1-16, 2019.

[4] C. Cefai, P. A. Bartolo, V. Cavioni, and P. Downes, "Strengthening Social and Emotional Education as a Core CurricularAarea across the EU: A Review of the International Evidence Analytical Report," Luxemburg, 2018.

[5] M. Garrote Salazar and M. Fernández Agüero, "Intercultural Competence in Teaching: Defining the Intercultural Profile of Student Teachers," in Bellaterra Journal of Teaching \& Learning Language \& Literature, 2016, vol. 9, no. 4, pp. 4158.

[6] E. Achkovska-Leshkovska and V. Davchev, "Intercultural Education: Analysis of The Primary School Textbooks in The Republic of Macedonia," Int. J. Cogn. Res. Sci. Eng. Educ., vol. 1, no. 2, pp. 51-56, 2013.

[7] P. Dusi, M. Rodorigo, and P. A. Aristo, "Teaching in Our Society: Primary Teachers and Intercultural Competencies," in 7th International Conference on Intercultural Education "Education, Health and ICT for a Transcultural World," 2016, vol. 237, no. June 2016, pp. 96-102.

[8] Z. Habib, "International Mindedness and Intercultural Competence: Perceptions of Pakistani Higher Education Faculty," J. Educ. Educ. Dev., vol. 5, no. 1, p. 60, 2018. 
[9] Y. Zhao, "Preparing Globally Competence Teachers: A New Imperative for Teacher Education," J. Teach. Educ., vol. 61, no. 5, pp. 422-431, 1010.

[10] E. Van Laar, V. A. J. A. M. Van Deursen, J. A. G. M. Van Dijk, and J. de Haan, "The Relation between 21st-Century Skill \& Digital Skills: A Systematic Literature Review," Comput. Hum. Behav., vol. 72, pp. 577-588, 2017.

[11] B. H. Ramos, "Towards the Development of Intercultural Competence Skills: A Pedagogical Experience with Pre-Service Teachers," HOW, A Colomb. J. Teach. English, vol. 20, pp. 206-225, 2013.

[12] J. Gundara, "Religion, Human Rights \& Intercultural Education," Intercult. Educ., vol. 11, no. 2, pp. 127-136, 2010.

[13] W. B. Gudykunst and Y. Y. Kim, communicating with Strangers: An Approach to Intercultural Communication. Shanghai: Shanghai Foreign Language Education Press, 2007.

[14] Q. Cui, “A Study of Factors Influencing Students’ Intercultural Competence,” J. Lang. Teach. Res., vol. 7, no. 3, p. 433, 2016.

[15] I. Tuncel and A. Aricioglu, "The Factors Affecting The Intercultural Sensitivity Perception Level of Psychological Counseling and Guidance Students," Int. Educ. Stud., vol. 11, no. 3, pp. 61-69, 2018.

[16] B. Leutwyler, C. Mantel, D. S. Petrovi, B. M. Dimitrijevi, and B. Zlatkovic, "Teachers' Beliefs about Intercultural Education: Different Levels of Intercultural Sensitivity in Schooling and Teaching," Educ. Res., vol. 5, no. 8, pp. 280-289, 2014.

[17] A. Paraskevi and M. Nikolaos, "Students from Different Cultural Backgrounds, Their Difficulties upon Elementary School Entry in Greece and Teachers' Intercultural Educational Practices," Br. J. Educ., vol. 5, no. 4, pp. 2053-5813, 2017.

[18] T. Rog, "Intercultural education at Pre-school Level in The Context of Polish Kindergarten Curriculum Changes," J. Linguist. Intercult. Educ., pp. 179-201, 8AD.

[19] R. Osad'an, E. Reid, and M. Belešová, "Intercultural Primary Education in the Second Half of the Decade," Acta Technol. Dubnicae, vol. 6, no. 2, pp. 77-86, 2016.

[20] J. A. Banks, "The dimensions of Multicultural Education," Multicult. Lead., vol. 4, pp. 5-6, 1991.

[21] M. E. M. Hernández and A. D. C. H. Hermosilla, "An Intercultural Education: Teaching Reading in a Mapuche Context,” Int. Educ. Stud., vol. 8, no. 10, pp. 28-39, 2015.

[22] X. Papavasiliou, "Intercultural education Outline through The Views of Primary education Teachers at Regional Unit of Trikala (Master Thesis)," 2015. [Online]. Available: https://dspace.lib.uom.gr/bitsream/2159/17537/3/PapavasileiouChristosMsc2015.pdf. [Accessed: 15-Jun-2019].

[23] A. Takeuchi, "Developing A Scale of Children 's Intercultural Competence: Issues and Challenges," vol. March, no. 15, pp. 45-58, 2015.

[24] Y. Rakovskaya, "Developing Intercultural Competence through Cultural Diversity at School," 2015.

[25] M. J. Bennet, "Becoming Interculturally Competent," in The Diversity Symposium Proceedings: An Interin Step toward A Conceptual Framework for The Practice of Diversity, 2004.

[26] L. Sercu, "teaching Foreign languages in an Intercultural World," in Foreign Language Teachers and Intercultural Competence, L. Sercu, Ed. New York: Multilingual Matters, Ltd, 2005, pp. 1-18. 
[27] M. W. Lustig and J. Koester, "The Behavioral assessment Scale for Intercultural Communication Effectiveness," Int. J. Intercult. Relations, vol. 12, no. 3, pp. 233246, 1988.

[28] G. G. Hiller and M. Wozniak, "Developing An Intercultural Competence Programme at An International Cross-border Univerversity," Intercult. Educ., vol. 20, no. 4, pp. 113-124, 2009.

[29] S. Demirciouglu and C. Cakir, "Intercultural Competence of Students in International Baccalaureate World Schools in Turkey and Abroad," Int. Educ. Stud., vol. 9, no. 9, pp. 1-14, 2016.

[30] A. S. Arslangilay, "The Reflection of Immigration on School Culture: A Qualitative Study," Int. J. Instr., vol. 11, no. 2, pp. 585-602, 2018.

[31] C. T. H. Hoa and T. Vien, "The Integration of Intercultural Education into Teaching English: What Vietnamese Teachers Do and Say," Int. J. Instr., vol. 12, no. 1, pp. 441-456, 2019.

[32] W. Sintawati, "Intercultural Learning Supported by Technology: A Small-scale Systematic Review," Int. J. Educ. Learn., vol. 1, no. 1, pp. 33-41, 2019.

[33] E. harmandaoglu Baz and K. U. Isisag, "Promoting Intercultural Competence of Turkish EFL Pre-service Teachers via Twitter,” J. Langugae Linguist. Stud., vol. 14, no. 3, pp. 104-132, 2018.

[34] Council of Europe, Common European Framework of Reference for Language Learning, Teaching, and Assessment. Cambridge: Cambridge University Press, 2001.

[35] D. Atay, "Reflection on the Cultural Dimension of Language Teaching," Lang. Intercult. Commun., vol. 5, no. 3, pp. 222-236, 2005. 